\title{
Carcinoid tumour behind bronchiectasis
}

\author{
N. Charokopos'1, M. Tsiamita1, K. Karkoulias¹, D. Koumoundourou², \\ C. Aletra2 ${ }^{2}$ D. Dougenis 3 , K. Spiropoulos 1
}

ABSTRACT: Carcinoid tumour behind bronchiectasis. $N$. Charokopos, M. Tsiamita, K. Karkoulias, D. Koumoundourou, C. Aletra ${ }^{2}$, D. Dougenis ${ }^{3}$, K. Spiropoulos.

This report describes a female patient with bronchiectasis, presented to our department with recurrent hemoptysis. Bronchoscopy revealed nothing else but blood arising from the upper lobe bronchus. High resolution com- puting tomography of the lung (HRCT) revealed bronchiectasis of the upper lobe. A right upper lobectomy was performed. Behind bronchiectasis multiple nodular lesions, 5-10 mm were observed. Histological and immunohistochemical examination revealed findings consistent with peripheral typical bronchial carcinoids. Monaldi Arch Chest Dis 2006; 65: 2, 110-113.

Key words: Bronchiectasis, carcinoid tumour.

1 Division of Pulmonology, Internal medicine Department,

2 Department of pathology,

3 Department of cardiothoracic surgery,

Medical School of Patras, Regional University Hospital, Patras, Greece.

Correspondence: Assoc. Prof. Spiropoulos K; Medical School of Patras; Regional University Hospital; 26500 Rio-PatrasGreece; e-mail: kkarkoul@fremail.gr

Carcinoids tumours belong to neuroendocrine tumours (NETs), which occur in tissues that contain cells derived from the embryonic neural crest neuroectoderm and endoderm [1]. Pulmonary NETs consist of a group of distinct lesions with a spectrum of differentiation and clinical behaviour ranging from incidental small proliferation of neuroendocrine cells (tumourlets) to small cell lung cancer [2]. Incidental findings of tumourlets in bronchiectasis have been described in the literature $[3,4]$ but the real clinical meaning is controversial. Both typical carcinoid tumour and bronchiectasis is a quite rare condition. A review of the pertinent literature revealed a few reports on carcinoid tumour presented in this manner $[5,6]$.

Here, we report the case of a patient with both long-standing bronchiectasis and carcinoid tumour. Possible pathogenic mechanisms are discussed.

\section{Case report}

A 50-year-old non-smoking woman was admitted to the emergency department in May 2002 with recurrent hemoptysis. She reported several episodes of hemoptysis in the past, which were treated with antibiotics, by her primary physician. The physical examination revealed a patient in good nutritional status, a temperature of $37.4{ }^{\circ} \mathrm{C}$, heart rate 110 beats/min and a blood pressure of 110/60 $\mathrm{mmHg}$. Her respiratory rate was increased ( 25 breaths/min). Lung auscultation revealed inspiratory and expiratory rales of the right hemithorax. Her abdomen was soft, non-tender with normal bowel sounds. The ini- tial laboratory data revealed a WBC count of 7X103 $\mu \mathrm{l}$, a slight decrease of hematocrit to $35 \%$ and platelet count of $250 \times 10^{3} \mu \mathrm{l}$. Examination of the upper respiratory tract revealed blood on the vocal cords emerging from the trachea with no other abnormalities. A standard chest radiograph revealed an increased density of the upper lobe with dilated bronchi, which suggested bronchiectasis. Flexible bronchoscopy revealed fresh blood emerging from the bronchi of the upper lobe. An High Resolution Computed Tomography (HRCT) of the lungs revealed volume loss and cylindrical bronchiectasis throughout the upper lobe without other findings (fig. 1). On retrospective examination of the patients CT studies, multiple nodular lesions were found to

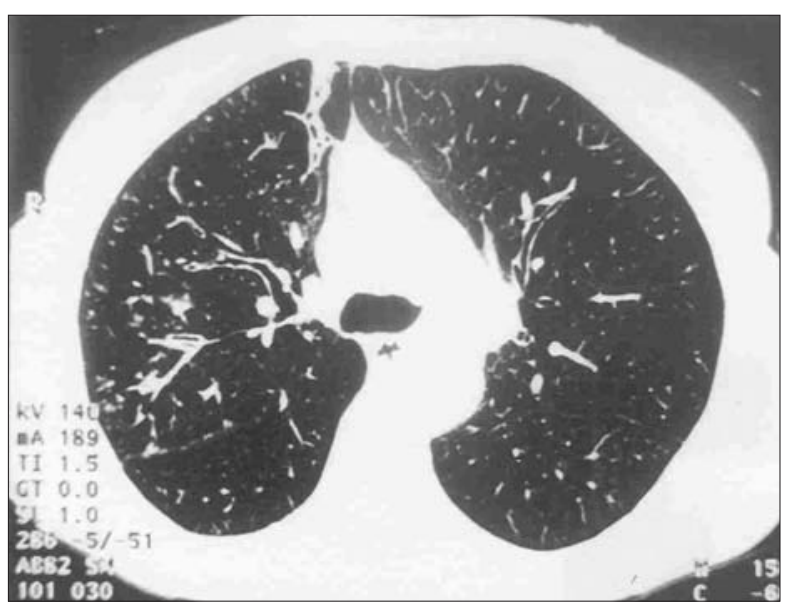

Fig. 1. - HRCT of the lung revealed cylindrical bronchiectasis throughout the upper lobe. 
be present adjacent to the bronchiectasis. Treatment with intravenous clarithromycin and cefuroxime begun. Five days after the admission the patient was in good condition without hemoptysis. Because of the several episodes due to hemoptysis in the past a right upper lobectomy was performed, which is the best curative method for severe and localised bronchiectasis. The submitted specimen was a right upper lobe (RUL) of the lung. On gross examination RUL revealed, dilated bronchi and areas of fibrosis. This process was also evident in bronchioles, which were partially obstructed by secretions. On microscopic examination cylindrical-type bronchiectatic lesions were identified throughout the RUL; bronchiectasis also involved the small bronchioles with a discrete amount of fibrosis. There were several well-circumscribed but not encapsulated nodules 5-10 $\mathrm{mm}$, situated at the periphery of bronchioles and in the vicinity of subpleural parenchyma.

The nodules consisted of nests of tumour cells, with ill-defined infiltrative margin, showed trabeculae-like formation and rare foci of necrosis. The tumour cells had finely granular eosinophilic cytoplasm, with a moderate degree of nuclear pleomorfism. Immunohistochemical staining showed an intense-positivity for chromogranin A, synaptophysin, neuron-specific-enolase, cytokeratines (AE1/AE3, CK19, CK18), while they were negative for S-100 protein, CEA, PCEA, gastrin, CK20 and CK7. The cells were also sporadically reactive to adremocorticotopin (ACTH). The mitotic ratio was very low consisting of 2-3 mitoses per 10 high power fields. No lymphatic or blood vessel invasion was observed. The diagnosis was that of a typical carcinoid of the lung (fig. 2, 3). Computing tomography of the upper and lower abdomen was normal. On retrospective examination of the patients CT studies, multiple nodular lesions were found to be present adjacent to the bronchiectasis The serum concentrations of ACTH prolactin, serotonin, gastrin and insulin were all within normal values.

\section{Discussion}

This patient had severe localised bronchiectasis, which was treated by surgical lobectomy. Car-

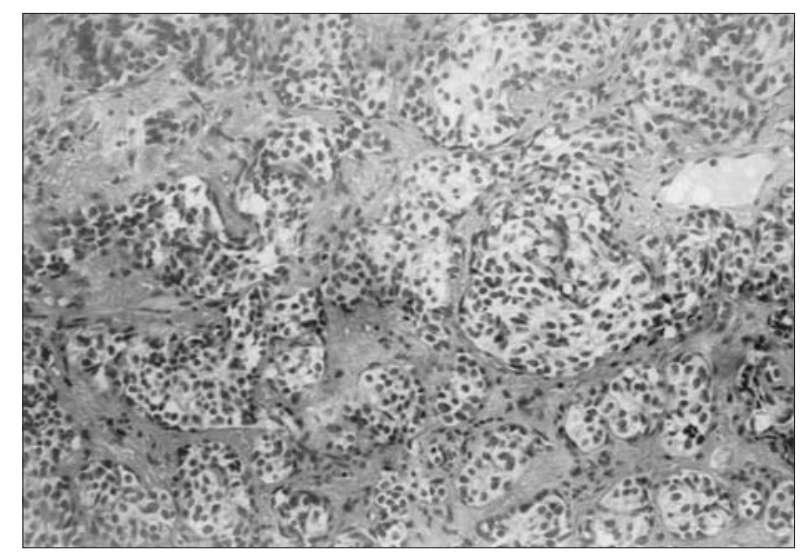

Fig. 2. - Typical carcinoid of the lung: The tumour cells form nests and trabeculae. Hematoxylin/ eosine (x10). cinoids tumours were an incidental finding. Bronchial carcinoid tumours belong to NETs of the lung. They arise in bronchial and bronchiolar epithelium and may derive from kulchitsky cells neuroepithelial bodies or pluripotential epithelial cells $[1,2]$, accounting for about $2 \%$ of primary lung tumours. The exact role of NE-cells is not well understood although it is suggested that NEcells derived peptides may have important paracrine regulatory and mitogenic function for bronchial epithelial cells, fibroblasts, and mast cells. Fetal lungs, as compared with adult lungs, have an abundance of neuroendocrine cells [7]. In addition, hypoxia and extended exposure to pollutants such as asbestos, nitrosamine, naphalene, ozone, and cigarette smoking [8, 9, 10, 11, 12] may induce hyperplasia of NE- cells derived peptides in bronchial and bronchiolar mucosa. Carcinoid tumours are perplexing neoplasms. They include foci of neuroendocrine-cell hyperplasia (tumorlets), lesions that rarely metastasise (typical carcinoid tumours), lesions that occasionally metastasise (atypical carcinoid), lesions that quite often recur after lung resection (large cell neuroendocrine carcinoma), and lesions that so commonly metastasize and are consider the prototypical cancer (small-cell carcinoma). Tumourlets are frequently observed in adults living at high altitude, after acute lung injury [8], in eosinophilic granuloma [13], tuberculosis [14], interstitial lung disease [15], cystic fibrosis [16], Cushing's syndrome [17], oblliterative bronchiolitis [18, 19, 20], and bronchiectasis $[3,4,5]$. In order to specify the spectrum of these tumours and to reduce confusions between pathologists and clinicians, the WHO classification of pulmonary neuroendocrine tumours of 1981 was replaced in 1999 by a new one aiming at a simple morphological, clinical and therapeutic differentiation [18].

According to this classification the spectrum of pulmonary NETs begins from neuroendocrine cell hyperplasia and tumourlets, typical carcinoid, atypical carcinoid, large cell neuroendocrine carcinoma, and small cell lung carcinoma. The new WHO classification of neuroendocrine lung tumours is based on histological criteria such as neuroendocrine morphology, nuclear features,

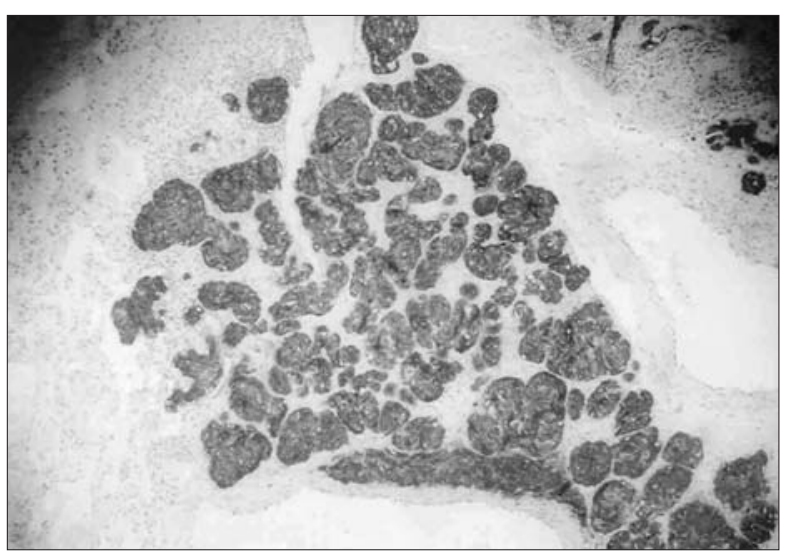

Fig. 3. - The tumour cells showed intense positivity for chromogranin A $(x 2,5)$. 
presence or absence of necrosis, and mitotic counts as well as on immunohistochemical findings. Arrigoni et al. defined as atypical carcinoid with increased mitotic activity (5-10 mitosis/2 $\mathrm{mm}^{2}$ ) [21], Travis et al. redefined it with correlation to the mitotic activity with the survival data [22]. According to the new classification a mitotic activity ranging from 2-10 mitosis per $2 \mathrm{~mm}^{2}$ or the presence of necrosis is accepted. Concerning the diagnosis of the different entities of neuroendocrine tumours, it should also be considered the influence of the size of the tissue sample on the accuracy and feasibility of the diagnosis. In our case several peripheral lesions $5-10 \mathrm{~mm}$ behind bronchiectasis were detected, without metastasizing to mediastinal lymph nodes and with immunoreactivity to chromogranin A which is the most useful immunohistochemical marker in typical carcinoid followed by synaptophysin and Leu-7 [2, 23] rare foci of necrosis and a very low mitotic ratio. So far there are many reports of tumourlets showed histologic and immunohistochemical criteria of typical carcinoid tumours on the other hand typical tumourlet may occur in proximity or at a distance from the carcinoid tumour and as a result diagnosis may be difficult [24]. The majority of bronchial carcinoids are usually solitary masses, larger than $5 \mathrm{~mm}$ perihilar in location, and patients often present with recurrent pneumonia, cough, hemoptysis, or chest pain. Typical carcinoid tumours are usually indolent, with metastases reported in less than 10 percent of the cases [25]. However, a small number of typical carcinoids may be arise in the peripheral lung fields or adjacent to the pleura [26, 27]. Pulmonary tumourlets are smaller than $5 \mathrm{~mm}$ [22] peripheral, and multiple. The pathological features that distinguish tumourlets from bronchial carcinoids are the lack of a capsule (except for a fibrolamellar membrane encircling the nests) the lack of a vascular supply (except for primitive lymphatic ducts) without mitoses in tumourlets $[22,28]$. The malignant potential of tumourlets has been apparent since their resemblance to bronchial carcinoids was noted [29, 30]. However, metastases to bronchopulmonary, hilar, and mediastinal lymph nodes or more distant sites have been reported in only a few patients [31]. Promising data in distinguishing tumourlets from typical carcinoids comes from the study of Finkelstein et al [32] who observed genotyping differences between typical carcinoid and tumourlets. On the other hand, the differential diagnosis between typical and atypical carcinoid may be difficult also. Atypical carcinoids [33], occur in older patients, most commonly in the sixth decade of their life and they tend to be larger than well differentiated neuroendocrine tumours and occur more commonly in the peripheral lung fields. Atypical carcinoids have an aggressive clinical course, metastasizing to mediastinal lymph nodes in 30 to 50 percent of cases.

Airway remodeling and chronic inflammation may promote NE-cell hyperplasia. Miller et al [19] reviewed 25 consecutive patients undergoing lung resection for peripheral carcinoid tumour showed that nineteen patients had NE cells hyperplasia and eight patients had findings consistent with obliterative bronchiolitis. The above author emphasized the relationship between bronchial carcinoid and airflow obstruction further more Aguayo [13] demonstrated, that NE-cell hyperplasia and airway remodeling co-exist even in patients in whom there is no obvious explanation for airway disease and chronic airflow obstruction. In our case multiple carcinoids tumours there were several well defined but not encapsulated nodules 5-10 $\mathrm{mm}$, located at the periphery of bronchioles and in the vicinity from the pleura. The features of chronic inflammation and airway remodeling may suggest that carcinoids might be a hyperplastic response of NE-cells of bronchiectasis. Alternatively the finding that pulmonary tumourlets are often observed in bronchiectatic lungs raises the possibility of a field effect on carcinoid tumour formation.

In conclusion, the findings in the present case suggest that it is prudent to consider the existence of a carcinoid tumour in patients with long standing bronchiectasis.

\section{References}

1. Oberg K. Carcinoid Tumors: molecular genetics, tumor biology and update of diagnosis and treatment. Curr Opin Oncol 2002; 14: 38-45.

2. Leothela PD, Jauch A, Holtgreve-Grez H, Thakker RV. Genetics of Neuroendocrine and carcinoid tumors. Edocr Relat Cancer 2003; 10: 437-500.

3. Klinke F, Blanco A, Muller B, Bosse V. The tumorlet carcinoid in bronchiectasis-changed lung. An example of a multifocal, endocrine tumour. Pneumologie 1990; 44 (Supp11): 607-609.

4. Dewan M, Malatani TS, Osinowo O, al-Nour M. Zahrani ME. Carcinoid tumorlets associated with diffuse bronchiectasis and intralobar sequestration. JR Soc Health 2000; 12: 192-5.

5. Canessa PA, Santini D, Zanelli M, Capecchi V. Pulmonary tumorlets and microcarcinoids in bronchiectasis. Monaldi Arch Chest Dis 1997; 52: 138-139.

6. Cunnigham GJ, Nassau E, Walter JB. The frequency of tumor-like. Formation in bronchiectatic lungs. Thorax 1958; 13: 64-68.

7. Spindel ER,Sunday ME, Hofler H, Wolfe HJ, Habener JF, Whin WW. Transient elevation of messenger RNA encoding gastrin releasing peptide, a putative pulmonary growth factor in human fetal lung. J Clin Invest 1987; 80: 1172-1179.

8. Stevens TP, McBride JT, Peake JL, Pinkerton KE, Stripp BR. Cell proliferation contributes to PNEC hyperplasia after acute airway injury. Am J Physiol 1997; 272: 486-93.

9. Aguayo SM, Mandeleine A, Kane A, King JR, Schwarz MI, Grauer L, Miller YE. Increased levels of bombesinlike peptides in the lower respiratory tract of asymptomatic cigarette smokers. J Clin Invest 84: 1105-1113.

10. Johnson NF, Wagner JC, Wills HA. Endocrine cell proliferation in the rat lung following asbestos inhalation. Lung 1980; 158: 221-228.

11. Linoila RI . Effects of diethylnitrosamine on lung neuroendocrine cells. Exp Lung Res 1982; 3: 225-236.

12. Lauweryns JM, Cokelaere M, Lerut T. Cross circulation studies on the influence of hypoxia and hypoxemia on neuro-epithelial bodies in young rabbits. Cell Tissue Res 1978; 193: 373-386. 
13. Aguayo SM, Tallmadge E, King JR, James A, Waldron JR, Karen M, et al. Increased Pulmonary Neuroendocrine cells with bombesin-like immunoreactivity in adult patients with eosinophilic granuloma. J Clin Invest 1990; 86: 838-844.

14. Marchevsky A, Nieburgs HE, Olenko E, Kirschner P, Teirstein A, Kleinerman J. Pulmonary tumorlets in cases of tuberculoma of the lung with malignant cells in brush biopsy. Acta Cytol 1982 ; 26: 491-494.

15. Miller MA, Mark GJ, Kanarek D. Multiple peipheral pulmonary carcinoids and tumorlets of carcinoid type, with restrictive and obstructive lung disease. Am J Med 1978; 65: 373-378.

16. Johnson DE, Wobken DJ, Landrum BG. Changing, bombesin, calcitonin and serotonin in immunoreactive pulmonary neuroendocrine cells in cystic fibrosis and after prolonged mechanical ventilation. An Rev Resp Dis 1988; 137: 123-131.

17. Rodgers-Sallivan RF, Weiland LH, Palumbo PJ, Hepper NG. Pulmonary tumorlets associated with Cushing's syndrome. An Rev Resp Dis 1978; 117: 799-806.

18. Watanabe H, Kobayashi H, Homma K, Ohnishi Y, Iwafuchi M. Diffuse panbrochiolitis with multiple tumorlets. A quantitave study of the Kultschitzky cells and the clusters. Acta Pathol Jpn 1985; 35: 1221-31.

19. Miller RR, Muller Nl. Neuroendocine cell hyperplasia and obliterative bronchiolitis. Am J Surg Pathol 1995; 19: 653-8.

20. Sherin N, Harrison NK, Shepard MN, Hansell DM, Yacoub M, Clark TJ. Obliterative bronchiolitis caused by multiple tumorlets and microcarcinoids successfully treated by single lung transplantation. Thorax 1995; 50: 207-9.

21. Arrigoni MG, Woolner LB, Bernatz BE. Atypical carcinoid tumours of the lung. J Thorac Cardiovasc Surg 1972; 64: 413-21

22. Travis WD, Colby TV, Corrin B, Shimosato Y, Brambilla E. World Health Organization, Histological Typing of lung and pleural tumours. 3rd ed. Berlin: Springer; 1999.
23. Vadasz P, Palffy G, Egervary M, Schaff Z. Diagnosis and treatment of bronchial carcinoid tumors. clinical and pathological review of 120 operated patients. Eur J Cardiothorac Surg 1993; 7: 8-11.

24. Bonikos DS, Archibald R, Bensch KG. On the origin of the so-called tumorlets of the lung. Hum Pathol 1976; 7: 461-469.

25. McCaughan BC, Martini N, Bains MS. Bronchial carcinoids. Review of 124 cases. J Thorac Cardiovasc Surg 1985; 89: 8-17.

26. Skinner C, Ewen SWB. Carcinoid lung: diffuse pulmonary infiltration by a multifocal bronchial carcinoid. Thorax 1976; 31: 212-219.

27. Bonikos MG, Bench KG, Jamblis RW. Peripheral pulmonary carcinoid tumours. Cancer 1976; 37: $1977-$ 1998.

28. Churg A, Warnock ML. Pulmonary tumorlet. A form of peripheral carcinoid. Cancer 1976; 37: 1469-1477.

29. Liu SM, Hsing-Hsien $\mathrm{Wu}$, Chien- Jen Wu, Chien-Long Kuo, Lein-Ray Mo. Adrenocorticotropin-producing pulmonary tumorlets with lymph node metastasis. Pathol Intern 2003; 53: 883-886.

30. Arioglou E, Doppman J, Gomes M, Kleiner, Mauro D, Barlow C, Papanicolaou D. Cushings syndrome caused by corticotropin secretion by pulmonary tumorlets. $N$ Engl Med 1998; 24: 883-886.

31. D'Agati VD, Ferzin KH. Carcinoid tumorlets of the lung with metastasis to a peribronchial lymph node - report of a case and review of the literature. Cancer 1985; 55: 2472-2476

32. Finkelstein SD, Hasegaw T, Colby T, Yousenm SA 11q13 Allelic Imbalance Discriminates Pulmonary Carcinoids from tumorlets. A microdissection Based Genotyping Aprroach useful in clinical practice. Am J Pathol 1999; 153: 633-634.

33. Travis WD, Rush W, Flieder DB. FalkR, Fleming MV, Gal AA, Koss MN. Survival analysis of 200 pulmonary neuroenfocrine tumours with clarification of criteria for atypical carcinoid and its separation from typical carcinoid. Am J Surg Pathol 1998 Aug; 22: 934-44.

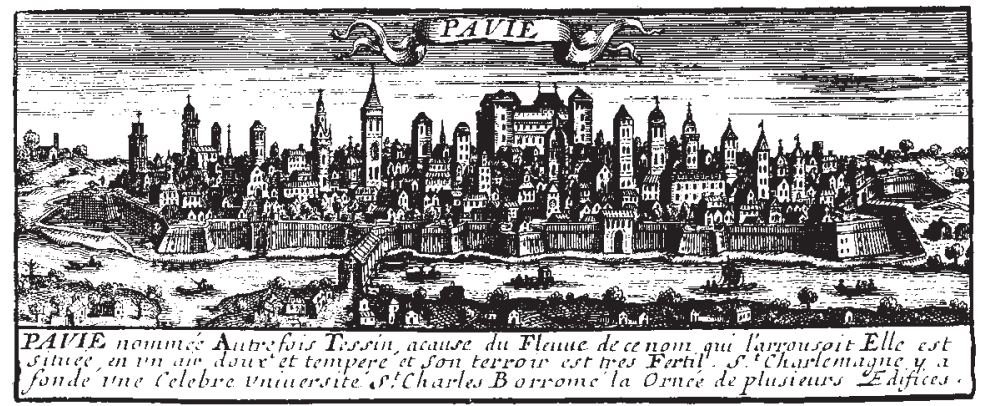

